\title{
Intensity modulated radiotherapy with concurrent chemotherapy for larynx preservation of advanced resectable hypopharyngeal cancer
}

\author{
Wen-Yen Huang ${ }^{1}$, Yee-Min Jen*1, Chang-Ming Chen'1, Yu-Fu Su'1, Chun-Shu Lin'1, Yaoh-Shiang Lin², Ying-Nan Chang², \\ Hsing-Lung Chao ${ }^{1}$, Kuen-Tze Lin' ${ }^{1}$ and Li-Ping Chang ${ }^{1}$
}

\begin{abstract}
Background: To analyze the rate of larynx preservation in patients of locally advanced hypopharyngeal cancer treated with intensity modulated radiotherapy (IMRT) plus concurrent chemotherapy, and compare the results with patients treated with primary surgery.

Methods: Between January 2003 and November 2007, 14 patients were treated with primary surgery and 33 patients were treated with concurrent chemoradiotherapy (CCRT) using IMRT technique. Survival rate, larynx preservation rate were calculated with the Kaplan-Meier method. Multivariate analysis was conducted for significant prognostic factors with Cox-regression method.

Results: The median follow-up was 19.4 months for all patients, and 25.8 months for those alive. The 5-year overall survival rate was $33 \%$ and $44 \%$ for primary surgery and definitive CCRT, respectively $(p=0.788)$. The 5 -year functional larynx-preservation survival after IMRT was $40 \%$. Acute toxicities were common, but usually tolerable. The rates of treatment-related mucositis ( $\geq$ grade 2 ) and pharyngitis ( $\geq$ grade 3 ) were higher in the CCRT group. For multivariate analysis, treatment response and cricoid cartilage invasion strongly correlated with survival.
\end{abstract}

Conclusions: IMRT plus concurrent chemotherapy may preserve the larynx without compromising survival. Further studies on new effective therapeutic agents are essential.

\section{Background}

Laryngopharyngectomy followed by radiotherapy (RT)/ chemoradiotherapy (CRT) has been one of treatment modalities for patients with hypopharyngeal cancer. However, it leads to the loss of a functional larynx. Larynx preservation modality for hypopharyngeal cancer has been tested in a trial conducted by the European Organization for Research and Treatment of Cancer (EORTC) Head and Neck Cancer Cooperative group [1]. It concludes that induction chemotherapy plus definitive RT offered $35 \%$ of 5 -year larynx preservation rate and does not compromise survival compared with surgery. Some retrospective studies show a 5-year overall survival varying widely from $14 \%$ to $43 \%$ after RT [2-4]. However, the

\footnotetext{
* Correspondence: yeeminjen@yahoo.com.tw

1 Department of Radiation Oncology, Tri-Service General Hospital, National Defense Medical Center, Taipei, Taiwan

Full list of author information is available at the end of the article
}

actual larynx preservation rate is seldom reported. Concurrent chemoradiotherapy (CCRT) has been thought to be better than sequential treatment from previous studies. Two important meta-analyses have concluded that the survival benefit from chemotherapy in head and neck cancer is based on concurrent, rather than induction use [5,6]. Nevertheless, there has been no randomized trial testing definitive CCRT versus surgery for hypopharyngeal cancer so far.

Intensity modulated radiotherapy (IMRT), a new RT technique, has the advantages of precise delivery, target conformity and normal tissue sparing. It is able to achieve a very high rate of locoregional control with less morbidity under optimal target delineation, appropriate physical quality control and accurate patient setup [7]. Although it has provided promising results in patients with other subsites of head-and-neck cancer [7-13], publications of using IMRT on hypopharyngeal cancer are rare. In our 
institution, CCRT has been one of the choices for resectable advanced hypopharyngeal cancer for more than 10 years and IMRT has been introduced since 2003. In this study, we analyze the rate of larynx preservation in patients of advanced resectable hypopharyngeal cancer after IMRT plus concurrent chemotherapy and compare the result with primary surgery.

\section{Methods \\ Patients}

We retrospectively reviewed medical records from January 2003 to November 2007 and identified 47 patients with histologically confirmed, previously untreated, locally advanced resectable squamous cell carcinoma of hypopharynx, who underwent primary surgery or definitive IMRT with concurrent platinum-based chemotherapy. Locally advanced resectable disease was defined as AJCC 2002 clinical stage II-IVA, excluding T1N0, small T2N0, T4b, N3, and M1 disease. Patients with T1-2N0 disease were excluded because they already had conspicuous success on larynx preservation using RT alone or CCRT, and rarely needed radical surgery. Those patients who had second primary cancer were excluded, too. The median age at diagnosis was 57, ranging from 40 to 73 . Pretreatment evaluation included medical history, physical examination, complete blood counts, serum biochemistries, laryngoscopy, upper GI panendoscopy, chest Xray, head and neck MRI and/or CT. Bone scan was conducted according to the clinical symptoms. Positron Emission Tomography was not routinely used for staging purpose. The information of advantages and disadvantages of different treatments were offered to all patients. The final treatment modalities depended on the patients' decision except for 3 patients who were assigned to CCRT; 1 with poor performance status $(E C O G=2)$ and 2 with severe medical comorbidity who could not undergo surgery under general anesthesia. The detailed patient characteristics were listed in Table 1.

\section{Surgery}

Fourteen patients underwent radical surgery as the primary treatment. These included 11 patients who had total laryngectomy with partial pharyngectomy and 3 patients who underwent total laryngectomy with total pharyngectomy. Ipsilateral thyroid lobectomy was conducted in 2 patients due to suspected thyroid gland involvement. All 14 patients also had neck dissection and 3 of them underwent bilateral neck dissection. The type of neck dissection was determined by the clinical nodal status individually. The general principle was ipsilateral modified radical neck dissection or supraomohyoid neck dissection for clinical N0 disease, ipsilateral modified radical neck dissection or extended neck dissection for
Table 1: Patient characteristics.

\begin{tabular}{|c|c|c|c|c|}
\hline & & \multicolumn{2}{|c|}{ Treatment } & \multirow[b]{2}{*}{$p$-value } \\
\hline & & $\begin{array}{c}\text { Surgery } \\
\text { No.(\%) }\end{array}$ & $\begin{array}{c}\text { CCRT } \\
\text { No.(\%) }\end{array}$ & \\
\hline No. of patients & & $14(30)$ & $33(70)$ & \\
\hline \multirow[t]{2}{*}{ Sex } & male & 13(93) & $32(97)$ & 0.523 \\
\hline & female & $1(7)$ & $1(3)$ & \\
\hline \multirow[t]{4}{*}{ Age(y) } & $\geq 60$ & $7(50)$ & $14(42)$ & 0.633 \\
\hline & $<60$ & $7(50)$ & $19(58)$ & \\
\hline & Median & 58 & 57 & \\
\hline & Range & $43-73$ & $40-71$ & \\
\hline \multirow{3}{*}{$\begin{array}{l}\text { Performance } \\
\text { (ECOG) }\end{array}$} & 0 & 10 & 23 & 0.805 \\
\hline & 1 & 4 & 9 & \\
\hline & 2 & 0 & 1 & \\
\hline \multirow[t]{3}{*}{ Location } & Pyriform sinus & $11(79)$ & $30(91)$ & 0.085 \\
\hline & Pharyngeal wall & $0(0)$ & $2(6)$ & \\
\hline & Post-cricoid & $3(21)$ & $1(3)$ & \\
\hline \multirow[t]{3}{*}{ Histology grade } & $1-2$ & $8(57)$ & $20(61)$ & 0.292 \\
\hline & 3 & $6(43)$ & $9(27)$ & \\
\hline & NA & $0(0)$ & $4(12)$ & \\
\hline \multirow[t]{4}{*}{ cT } & 1 & 0 & $1(3)$ & 0.795 \\
\hline & 2 & $3(21)$ & $7(21)$ & \\
\hline & 3 & $4(29)$ & $6(18)$ & \\
\hline & $4 a$ & $7(50)$ & 19(58) & \\
\hline \multirow[t]{3}{*}{$\mathrm{cN}$} & 0 & $5(36)$ & $9(27)$ & 0.488 \\
\hline & 1 & $1(7)$ & $7(21)$ & \\
\hline & $2 a-2 c$ & $8(57)$ & $17(52)$ & \\
\hline \multirow[t]{3}{*}{ Clinical stage } & $\|$ & $2(14)$ & $2(6)$ & 0.652 \\
\hline & III & $2(14)$ & $5(15)$ & \\
\hline & IVA & $10(71)$ & $26(79)$ & \\
\hline \multirow[t]{2}{*}{ cTCl } & Yes & $7(50)$ & $19(58)$ & 0.633 \\
\hline & No & $7(50)$ & $14(42)$ & \\
\hline \multirow[t]{2}{*}{$\mathrm{cCCl}$} & Yes & $2(14)$ & $7(21)$ & 0.581 \\
\hline & No & $12(86)$ & $26(79)$ & \\
\hline \multirow[t]{2}{*}{ RT dose(Gy) } & Median & 62 & 70 & \\
\hline & Range & $60-70$ & $70-75$ & \\
\hline \multirow{2}{*}{$\begin{array}{l}\text { Follow-up } \\
\text { time }(m)\end{array}$} & Median & 19.8 & 18.8 & \\
\hline & Range & 6.7-67.9 & $1.9-72.3$ & \\
\hline
\end{tabular}

Abbreviation: CCRT, concurrent chemoradiotherapy; ECOG, Eastern Cooperative Oncology Group; NA, not available; cT, clinical T stage; $\mathrm{CN}$, clinical N stage; $\mathrm{CTCl}$, clinical thyroid cartilage invasion; $\mathrm{CCCl}$, clinical cricoid cartilage invasion 
clinically positive-node disease. There were 21 nodes dissected on average. Pathological stages were identical to clinical stages in 10 patients. Another 4 patients had higher pathological stages than clinical stages.

\section{Radiotherapy technique}

All patients were immobilized in supine position using custom-made thermoplastic masks. CT simulation was conducted with 3-mm slice thickness (SIEMENS Simview NT simulator). All patients in CCRT group were treated with IMRT technique. Inverse treatment planning was performed using the Plato RTS computer system version 2.6.3 (Nucletron). There were usually 6 or 7 beams with a single isocenter. The gross tumor volume (GTV) was defined as grossly visible primary tumor and metastatic lymphadenopathy on image or physical examination. The high-risk clinical target volume (CTV2) encompassed the GTV, the pyriform sinus, post-cricoid area, retropharyngeal, parapharyngeal region and bilateral level II-III nodal area. The ipsilateral level IB and V were included if clinical nodal disease was present. Four patients underwent tracheostomy before RT to prevent airway obstruction; their tracheostoma sites were included in the CTV2. The low-risk clinical target volume (CTV3) included bilateral level IV and supraclavicular areas. The planning target volume 1 (PTV1) was GTV plus a $0.6-\mathrm{cm}$ margin. The PTV2, PTV3 was CTV2, CTV3 plus a $0.4-\mathrm{cm}$ margin, respectively. The median prescribed dose to the PTV1, PTV2, PTV3 was 70, 60, 50 Gy, respectively. In the primary surgery group, 10 patients had postoperative CCRT or RT alone. For postoperative IMRT, the median prescribed dose to the highrisk and low-risk area was 62 and $50 \mathrm{~Gy}$, respectively. The daily fraction dose to the PTV1 was 1.8-2.0 Gy, five fractions a week. All the PTVs were treated at the same time using simultaneous integrated boost (SIB) technique. The mean dose to the parotid glands was 26 Gy or lower if possible to reduce damage to salivary functions. The maximal dose of the spinal cord was kept below $45 \mathrm{~Gy}$. A pair of orthogonal radiographs or images taken from Elekta electronic portal imaging device were obtained to confirm positioning accuracy before the first day of treatment. Radiotherapy was delivered with $6 \mathrm{MV}$ photons from a linear accelerator (Precise, Elekta).

\section{Chemotherapy}

Chemotherapy included cisplatin +/- 5-fluorouracil. In the CCRT arm, 15 patients had cisplatin weekly (30 mg/ $\left.\mathrm{m}^{2}\right)$ for up to 8 cycles or tri-weekly $\left(60-80 \mathrm{mg} / \mathrm{m}^{2}\right)$ for 3 cycles. Eighteen patients had cisplatin $\left(60-80 \mathrm{mg} / \mathrm{m}^{2}\right.$ day 1) + 5-fluorouracil (800-1000 mg/m² day 1 to 4 ) every 3 to 4 weeks. The first cycle of chemotherapy was often given in the same week as the beginning of RT. Seven patients in the primary surgery group underwent adjuvant CCRT;
4 with cisplatin alone and 3 with cisplatin +5 -fluorouracil. The protocol of chemotherapy was adjusted by the medical oncologist according to the toxicity and patients' tolerance.

\section{Patient follow-up and toxicity evaluation}

All patients were examined weekly by laryngoscopy and physical examination during RT. Treatment response and toxicity were recorded by the radiation oncologist. After treatment, they were followed by both radiation oncologists and head \& neck surgeons 1-2 months for the first 6 months, and then every 3 months for 2 years, then every 4-6 months. History taking, physical examination, serum biochemistry, treatment-related toxicity evaluation, CT or MRI of head and neck and laryngoscopy were performed in the follow-up. The toxicity grading was based on Common Toxicity Criteria for Adverse Events (CTCAE) v3.0. Treatment response was assessed by the radiation oncologists and head and neck surgeons at 1 month after completion of RT according to the finding of laryngoscopy, CT or MRI, and physical examination. Biopsy or PET was conducted for the patients whose response grading was in controversy. Complete response (CR) was defined as complete disappearance of all lesions; Partial response (PR) was at least $50 \%$ decrease in dimension; Progressive disease (PD) was $25 \%$ increase; Stable disease (SD) was neither PR nor PD. Laryngectomy-free survival referred to patients who survived at the last follow-up without laryngectomy, regardless of hypopharynx-larynx function. Functional larynx-preservation survival was defined as survival with preservation of not only an intact hypopharynx-larynx, but also normal function. Larynx preservation rate was the rate of patients who never underwent laryngectomy, regardless of survival or functional preservation.

\section{Statistics}

Overall survival, locoregional progression-free survival, larynx-preservation survival rates were calculated with the Kaplan-Meier method, and the differences between groups in survival curves were examined using the logrank test. All of the tests were two-sided, and $\mathrm{p}<0.05$ was considered to be statistically significant. The differences of the patient characteristics between the 2 groups were examined with Chi-square test. Multivariate analysis was conducted for significant prognostic factors with Coxregression method. Analysis of the data was performed using SPSS 12 software.

\section{Results}

Survival

The median follow-up was 19.4 months for all patients, 19.8 months for surgery group and 18.8 months for CCRT group, respectively. In those alive, the median fol- 
low-up time was 25.8 months, ranging from 14.2 to 72.3 months. At the time of analysis, 23 patients were alive, 2 patients were lost to follow-up, and 22 patients had died; 20 died of disease, 1 died of heart attack, 1 died of esophageal cancer. The 2-year and 5-year overall survival of all patients was $57 \%$ and $37 \%$, respectively. The 5 -year overall survival rate was $33 \%$ and $44 \%$ for primary surgery and definitive CCRT, respectively $(\mathrm{p}=0.788$, Figure 1 ).

The 5-year disease-specific survival rate of primary surgery and CCRT group was $33 \%$ and $56 \%$, respectively $(\mathrm{p}=0.970)$. The 5 -year disease-free survival was $25 \%$ and $41 \%$, respectively $(\mathrm{p}=0.844)$. The 5 -year locoregional progression-free survival was $15 \%$ and $53 \%$, respectively $(p=0.365)$. Differences were not statistically significant. Loco-regional progression was the main cause of failure in both groups. The detailed patterns of failure were shown in Table. 2. Eleven patients had neck failure; 8 in the ipsilateral neck, 2 in the contralateral neck, and 1 in the tracheostoma site. All were in-field failure in the PTV2.

\section{Larynx preservation}

After definitive CCRT, the number of patients with CR, PR, SD, and PD was 16 (48\%), 15 (45\%), 1 (3\%), and 1 (3\%), respectively. Six patients underwent salvage surgery (1 neck dissection, 5 laryngectomy with neck dissection). One of them had pathological CR. One patient who completed CCRT had local recurrence and ultimately required tracheostomy. One additional patient with fixation of his hemilarynx at diagnosis experienced bilateral vocal cord palsy 1 month after completion of RT. He subsequently needed tracheostomy. Eventually, 22 patients

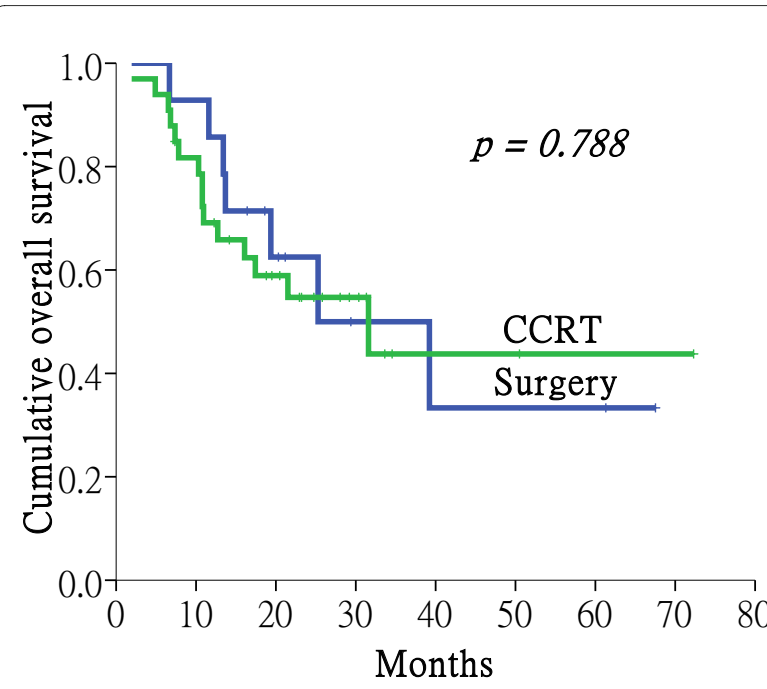

Figure 1 Overall survival of the primary surgery group vs. concurrent chemoradiotherapy (CCRT) group. The 5-year overall survival rate was $33 \%$ and $44 \%$ for primary surgery and definitive CCRT, respectively $(p=0.788)$ preserved a functional larynx. Figure 2 showed the functional larynx-preservation survival of the patients in CCRT group. The 5-year functional larynx-preservation survival, laryngectomy-free survival rate was $40 \%, 43 \%$, respectively.

\section{Prognostic factor analysis}

The result of univariate analysis of survival was shown in Table 3. Clinical $\mathrm{T}$ stage, thyroid cartilage invasion, cricoid cartilage invasion, worse performance status and treatment response significantly affected overall survival. For multivariate analysis, these 5 factors were included for evaluation of their effects on overall survival (Table 4.). Free of cricoid cartilage invasion and CR after treatment were significant predictors for better overall sur$\operatorname{vival}(\mathrm{p}=0.043$ and $<0.001$, respectively).

Treatment response was the most important prognostic factor. In CCRT group, the 16 patients with CR had $75 \% 5$-year overall survival, which was significantly better than non-CR patients. All non-CR patients who did not undergo salvage laryngectomy eventually died within 2 years. Five patients who underwent salvage laryngectomy had a 2 -year survival rate of $40 \%$.

\section{Toxicity}

Acute and late toxicities were listed in Table 5. Acute pharyngitis was the most common sequela and developed in virtually all of the patients. The rates of mucositis $(\geq$ grade 2 ) and pharyngitis ( $\geq$ grade 3 ) were higher in the CCRT group. Since both groups used the same fractionation dose, this was probably due to the higher total radiation dose in the CCRT group (70-75 Gy vs. 60-70 Gy). Three patients in the CCRT group suffered from grade 4 leukopenia. There were 4 patients who had RT interruption more than 5 days due to toxicities ( 3 grade 3 leukopenia, 1 grade 3 pharyngitis). In general, CCRT was tolerable for most patients.

Two patients had severe late toxicities and ultimately failed to retain a functional larynx in the CCRT group. One needed tracheostomy because of bilateral vocal cord palsy. The other became feeding tube-dependent after salvage laryngectomy. Xerostomia was mild and continued to decrease over time from the end of RT. Only one patient complained of grade 2 xerostomia at 1 year after treatment. Her average dose of the bilateral parotid glands was 25.9 and $23.1 \mathrm{~Gy}$.

Previous CCRT did not increase perioperative complication rate in the subsequent salvage surgery. For the six patients who underwent salvage surgery, 2 experienced surgery-related complications (1 with pharyngocutaneous fistula, 1 with wound infection). This complication rate was comparable to that of the primary surgery group. However, one patient who had T4aN1M0 disease and salvage pharyngolaryngoesophagectomy developed a 
Table 2: Patterns of failure after treatment

\begin{tabular}{lllll}
\hline Failure & $\begin{array}{l}\text { Primary surgery } \\
\text { No.(\%) }\end{array}$ & $\begin{array}{l}\text { Definitive CCRT } \\
\text { No.(\%) }\end{array}$ & $\begin{array}{l}\text { Total } \\
\text { No.(\%) }\end{array}$ \\
\hline None & $3(21)$ & $17(52)$ & $20(43)$ & 0.056 \\
LR alone & $6(43)$ & $11(33)$ & $17(36)$ & 0.534 \\
Distant alone & $1(7)$ & $2(6)$ & $10(6)$ & 0.890 \\
LR \& distant & $4(29)$ & $3(9)$ & $7(15)$ & 0.086 \\
Second cancer & $1(7)$ & $5(15)$ & $6(13)$ & 0.452 \\
\hline
\end{tabular}

Abbreviation: No., number; LR, loco-regional; CCRT, concurrent chemoradiotherapy

carotid artery rupture 4 months after surgery. He was rescued by an emergent ligation operation. He was still alive with no evidence of disease at the last follow-up.

\section{Discussion}

Our study shows that IMRT with concurrent chemotherapy demonstrated comparable results with primary surgery in terms of overall survival, disease-specific survival, and local control. The biggest reward is that it provides a 40\% 5-year larynx preservation survival rate. Table 6 shows the retrospective treatment results including larynx preservation rate in the literature of hypopharyngeal cancer after CCRT with IMRT technique [14,15].

Although CCRT is more effective for advanced head and neck cancer than RT alone, it may also be more toxic $[5,16]$. IMRT may spare more normal tissues, and has been shown to have decreased toxicities in head and neck

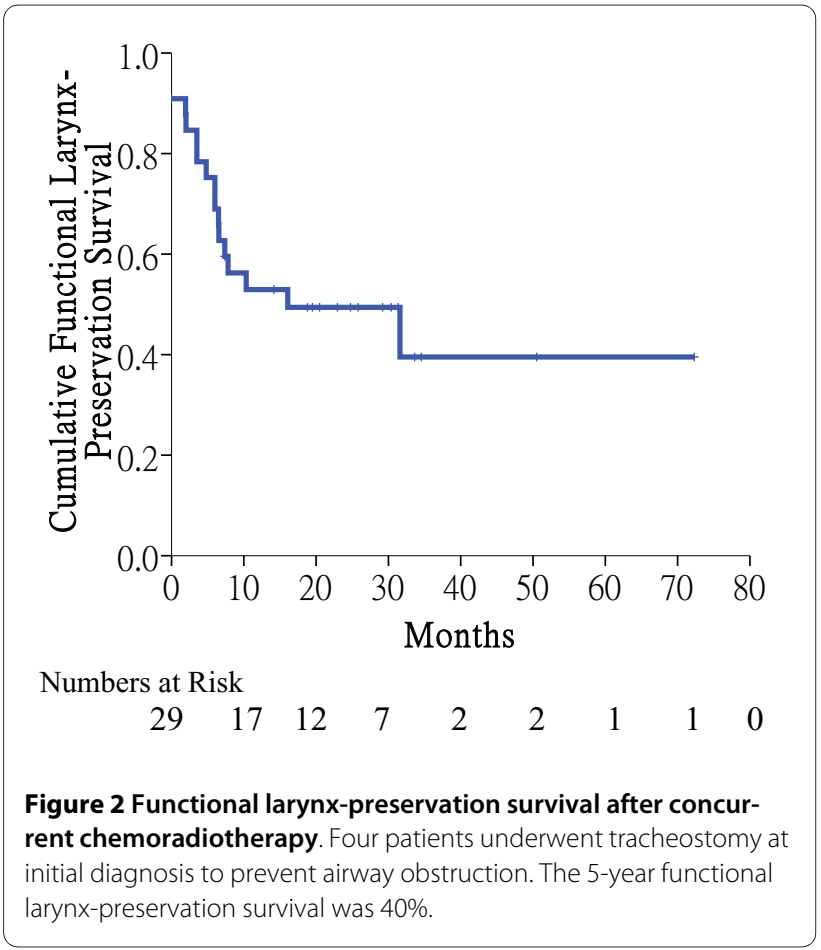

cancer [17-19]. In the present study, IMRT with concurrent chemotherapy is tolerable although there are more severe mucositis and pharyngitis. The interruption of RT due to toxicities is not common. It seems that the advantage of IMRT offsets the disadvantage of CCRT.

We recommend that all potential candidates of larynx preservation should be discussed in a multidisciplinary team to assess the justification, advantages and disadvantages. Besides, optimal delineation of target volume is a requirement. Our design of the PTV described in section "Methods, Radiation technique" is relatively small. However, there has been no out-field failure in the neck. Our

Table 3: Prognostic factors for overall survival in univariate analysis.

\begin{tabular}{lrr}
\hline Factors & \multicolumn{2}{c}{$p$-value } \\
\cline { 2 - 3 } & & \\
\cline { 2 - 3 } & & \\
\hline All patients & CCRT \\
Histology Grade 1-2 vs. 3 & 0.922 & 0.942 \\
Location Pyriform sinus vs. Pharyngeal wall & 0.995 & 0.768 \\
vs. Post-cricoid & 0.396 & 0.359 \\
Stage II-III. vs. IVA & & \\
CT stage T1-3 vs. T4a & 0.109 & 0.072 \\
cTCI Yes vs. No & 0.024 & 0.020 \\
cCCI Yes vs. No & 0.037 & 0.034 \\
CN stage N0-2a vs. N2b-2c & 0.003 & 0.010 \\
Performance(ECOG) 0 vs. 1-2 & 0.087 & 0.051 \\
Pretreatment hemoglobin $\leq 13$ vs. $>13$ gm/dl & 0.025 & 0.037 \\
Treatment modality Surgery vs. CCRT & 0.117 & 0.172 \\
Total RT day (CCRT group) $<60$ vs. $\geq 60$ days & 0.788 & \\
Treatment response CR vs. PR+SD+PD & & 0.568 \\
\hline
\end{tabular}

Abbreviation: CCRT, concurrent chemoradiotherapy; $\mathrm{CTCl}$, clinical thyroid cartilage invasion; $\mathrm{CCCl}$, clinical cricoid cartilage invasion; $C R$, complete response; $P R$, partial response; $S D$, stable disease; $\mathrm{PD}$, progressive disease 
Table 4: Prognostic factors for overall survival in multivariate analysis.

\begin{tabular}{|c|c|c|c|}
\hline \multirow[t]{2}{*}{ Factors } & \multirow{2}{*}{$\begin{array}{l}\text { 5-year overall } \\
\text { survival } \\
\text { (all patients) }\end{array}$} & \multicolumn{2}{|c|}{$p$-value } \\
\hline & & All patients & CCRT group \\
\hline cT stage & & 0.671 & 0.376 \\
\hline T1-3 & $67 \%$ & & \\
\hline $\mathrm{T} 4 \mathrm{a}$ & $16 \%$ & & \\
\hline cTCl & & 0.815 & 0.621 \\
\hline No & $68 \%$ & & \\
\hline Yes & $16 \%$ & & \\
\hline $\mathrm{cCCl}$ & & 0.023 & 0.020 \\
\hline No & $57 \%$ & & \\
\hline Yes & $0 \%$ & & \\
\hline Performance & & 0.443 & 0.990 \\
\hline ECOG 0 & $47 \%$ & & \\
\hline ECOG 1-2 & $0 \%$ & & \\
\hline Treatment response & & $<0.001$ & 0.001 \\
\hline$C R$ & $52 \%$ & & \\
\hline $\mathrm{PR}+\mathrm{SD}+\mathrm{PD}$ & $N A^{*}$ & & \\
\hline
\end{tabular}

Abbreviation: CCRT, concurrent chemoradiotherapy; $\mathrm{CTCl}$, clinical thyroid cartilage invasion; $\mathrm{CCCl}$, clinical cricoid cartilage invasion; $C R$, complete response; $P R$, partial response; $S D$, stable disease; PD, progressive disease; NA, not available

*The longest follow-up of this subgroup is 28 months and 2-year survival rate is $15 \%$.

guideline for target contouring appears to be reasonable and may serve as a reference.

Salvage surgery is necessary for non-CR patients. No non-CR patients who did not have salvage surgery were cured in this study. Therefore, it is essential to identify the non-CR patients to CCRT as early as possible. In our practice, we determined the response after a full dose of 70 Gy. This did not interfere with wound healing after salvage surgery. A randomized study may identify those potential patients for CCRT at a lower dose as in the laryngeal cancer [20].

There are at least two limitations in this study. First, it is a retrospective study from a single institute. Non-randomization, as well as low sample size, may make selection bias and comparison statistically inherently inappropriate. Second, we add a small margin $(6 \mathrm{~mm}$ around GTV) to create a PTV, concerning normal tissue damage. It's helpful to decrease treatment toxicities. However, this may be one of factors that compromise locoregional control.
Table 5: Treatment toxicities.

\begin{tabular}{|c|c|c|c|}
\hline & \multicolumn{3}{|c|}{ Patient number } \\
\hline & Surgery & CCRT & $p$-value \\
\hline Patients & 14 & 33 & \\
\hline \multicolumn{4}{|l|}{ Acute toxicities } \\
\hline Skin ( $\geq$ Gr. 2) & 5 & 6 & 0.194 \\
\hline Mucositis ( $\geq$ Gr. 2) & 1 & 13 & 0.027 \\
\hline Pharyngitis ( $\geq$ Gr. 2) & 9 & 29 & 0.060 \\
\hline Pharyngitis ( $\geq G r .3$ ) & 0 & 10 & 0.020 \\
\hline Leukopenia ( $\geq \mathrm{Gr} .3$ ) & 0 & 5 & 0.123 \\
\hline Anemia ( $\geq G r .2$ ) & 1 & 11 & 0.060 \\
\hline Weight loss ( $\geq G r .2$ ) & 4 & 13 & 0.480 \\
\hline Wound infection & 3 & $1^{*}$ & 0.039 \\
\hline Pharyngocutaneous fistula & 3 & $1^{*}$ & 0.039 \\
\hline \multicolumn{4}{|l|}{ Late toxicities } \\
\hline $\begin{array}{l}\text { Xerostomia at } 1 \mathrm{yr} \text { after treatment } \\
(\geq \mathrm{Gr} .2)\end{array}$ & 1 & 0 & 0.121 \\
\hline Neck fibrosis ( $\geq$ Gr. 2) & 3 & 3 & 0.246 \\
\hline Feeding tube-dependent & 0 & $1^{*}$ & 0.510 \\
\hline Dysphagia ( $\geq$ Gr. 2) & 0 & 2 & 0.347 \\
\hline Carotid artery blowout & 0 & $1^{*}$ & 0.510 \\
\hline Vocal cord palsy & & 4 & \\
\hline
\end{tabular}

Our IMRT using SIB technique with daily fractionation dose of 1.8-2 Gy to PTV1 results in approximate 1.5 Gy to the lower neck per day. This may be criticized for its probable radiobiological disadvantage. However, there is no in-field failure in the PTV3 in this study. In other series using IMRT with SIB in head and neck cancer, the daily dose to the lower neck is about $1.6 \mathrm{~Gy}$ and no higher failure rate is mentioned either [14]. There are indeed diverse dose fractionation regimens in practice of IMRT with SIB technique nowadays [21]. The long-term locoregional results in the low-risk area using different protocols are still unknown. A large prospective study with long-term follow-up is needed for creating standard regimens.

In our study, the patients have a $40 \%$ opportunity to retain their functional larynx which is an invaluable gain for every patient. This would be very cost-effective compared to the benefits of many cancer treatments that offer $10-20 \%$ locoregional control rate $[22,23]$.

Nearly all head and neck cancer expresses EGFR and it is correlated to an unfavorable prognosis [24-26]. In a phase III trial, adding cetuximab, an EGFR inhibitor, to 
Table 6: Studies of hypopharyngeal cancer treated with IMRT.

\begin{tabular}{|c|c|c|c|c|c|}
\hline Author (year) & Inclusion/Stage & Case no. & $\begin{array}{l}\text { Follow-up } \\
\text { (months) }\end{array}$ & Survival & $\begin{array}{l}\text { Larynx } \\
\text { Preservation }\end{array}$ \\
\hline Lee et al. (2007) [14] & $\begin{array}{l}\text { Retrospective review } \\
2002-2005 \text { Stage III-IV }\end{array}$ & 11 & 24 (median) & $53 \%$ (2-year OS) & $53 \%$ (2-year LFS) \\
\hline Studer et al. (2006) [15] & $\begin{array}{l}\text { Retrospective review } \\
2002-2005 \text { T1-4N0-3 }\end{array}$ & 29 & 16 (mean) & $90 \%$ (2-year DFS) & $96 \%(L P)$ \\
\hline this study (2010) & $\begin{array}{l}\text { Retrospective review } \\
\text { 2003-2007 T2-4aN0-2c }\end{array}$ & 33 & $\begin{array}{l}19 \text { (median) } \\
22 \text { (mean) }\end{array}$ & $\begin{array}{l}55 \% \text { (2-year OS) } \\
44 \% \text { (5-year OS) } \\
51 \% \text { (2-year DFS) } \\
41 \% \text { (5-year DFS) }\end{array}$ & $\begin{array}{l}54 \% \text { (2-year LFS) } \\
43 \% \text { (5-year LFS) } \\
49 \% \text { (2-year FLPS) } \\
40 \% \text { (5-year FLPS) }\end{array}$ \\
\hline
\end{tabular}

Abbreviation: IMRT, intensity modulated radiotherapy; OS, overall survival rate; DFS, disease-free survival rate; LFS: laryngectomy-free survival rate; LP: larynx preservation rate; FLPS: functional larynx-preservation survival rate

RT provided improvement in locoregional control and overall survival on squamous cell carcinoma of the head and neck [27]. However, only 15\% were patients of hypopharyngeal cancer in that study and subgroup analysis showed no statistical benefit for them. It is being investigated in an ongoing phase III trial (RTOG-0522) comparing CCRT with CCRT plus cetuximab in patients with stage III or IV squamous cell carcinoma of the oropharynx, hypopharynx, and larynx [28].

\section{Conclusions}

Locally advanced resectable hypopharyngeal cancer can be treated with IMRT plus concurrent chemotherapy, resulting in a 40\% 5-year functional larynx-preservation survival. This combined modality, although leading to more mucositis and pharyngitis, is tolerable. However, the prognosis is still poor. Further studies on new effective therapeutic agents are essential.

\section{Competing interests}

The authors declare that they have no competing interests.

\section{Authors' contributions}

WYH, YMJ, CSL carried study design. WYH, CMC collected the data and performed statistical analysis. WYH, YMJ, YFS drafted the manuscript. YSL, YNC took care of the patients and helped to draft the manuscript. HLC, KTL, LPC participated in manuscript preparation and gave advice on the work. All authors have read and approved the final manuscript.

\section{Acknowledgements}

This study was supported by grant TSGH-C96-10-S.

\section{Author Details}

'Department of Radiation Oncology, Tri-Service General Hospital, National Defense Medical Center, Taipei, Taiwan and ${ }^{2}$ Department of OtolaryngologyHead \& Neck Surgery, Tri-Service General Hospital, National Defense Medical Center, Taipei, Taiwan

Received: 19 February 2010 Accepted: 15 May 2010

Published: 15 May 2010

\section{References}

1. Lefebvre JL, Chevalier D, Luboinski B, Kirkpatrick A, Collette L, Sahmoud T: Larynx preservation in pyriform sinus cancer: preliminary results of a European Organization for Research and Treatment of Cancer phase III trial. EORTC Head and Neck Cancer Cooperative Group. J Natl Cancer Inst 1996, 88:890-99.

2. Kim S, Wu HG, Heo DS, Kim KH, Sung MW, Park Cl: Advanced hypopharyngeal carcinoma treatment results according to treatment modalities. Head Neck 2001, 23:713-17.

3. Lajtman Z, Manestar D: A comparison of surgery and radiotherapy in the management of advanced pyriform fossa carcinoma. Clin Otolaryngol Allied Sci 2001, 26:59-61.

4. Zelefsky MJ, Kraus DH, Pfister DG, Raben A, Shah JP, Strong EW, Spiro RH, Bosl GJ, Harrison LB: Combined chemotherapy and radiotherapy versus surgery and postoperative radiotherapy for advanced hypopharyngeal cancer. Head Neck 1996, 18:405-11.

5. El-Sayed S, Nelson N: Adjuvant and adjunctive chemotherapy in the management of squamous cell carcinoma of the head and neck region. A meta-analysis of prospective and randomized trials. $J$ Clin Oncol 1996, 14:838-47.

6. Pignon JP, le Maitre A, Maillard E, Bourhis J: Meta-analysis of chemotherapy in head and neck cancer (MACH-NC): an update on 93 randomised trials and 17,346 patients. Radiother Oncol 2009, 92:4-14.

7. Gregoire V, De Neve W, Eisbruch A, Lee N, Weyngaert D Van den, Van Gestel D: Intensity-modulated radiation therapy for head and neck carcinoma. Oncologist 2007, 12:555-64.

8. Lee N, Xia P, Quivey JM, Sultanem K, Poon I, Akazawa C, Akazawa P, Weinberg $V$, Fu KK: Intensity-modulated radiotherapy in the treatment of nasopharyngeal carcinoma: an update of the UCSF experience. Int J Radiat Oncol Biol Phys 2002, 53:12-22.

9. Eisbruch A, Ship JA, Dawson LA, Kim HM, Bradford CR, Terrell JE, Chepeha DB, Teknos TN, Hogikyan ND, Anzai Y, Marsh LH, Ten RK Haken, Wolf GT: Salivary gland sparing and improved target irradiation by conformal and intensity modulated irradiation of head and neck cancer. World J Surg 2003, 27:832-37.

10. Chao KS, Low DA, Perez CA, Purdy JA: Intensity-modulated radiation therapy in head and neck cancers: The Mallinckrodt experience. Int J Cancer 2000, 90:92-103.

11. Madani I, Bonte K, Vakaet L, Boterberg T, De Neve W: Intensity-modulated radiotherapy for sinonasal tumors: Ghent University Hospital update. Int J Radiat Oncol Biol Phys 2009, 73:424-32.

12. de Arruda FF, Puri DR, Zhung J, Narayana A, Wolden S, Hunt M, Stambuk H, Pfister D, Kraus D, Shaha A, Shah J, Lee NY: Intensity-modulated radiation therapy for the treatment of oropharyngeal carcinoma: the Memorial Sloan-Kettering Cancer Center experience. Int J Radiat Oncol Biol Phys 2006, 64:363-73.

13. Rosenbluth BD, Serrano V, Happersett L, Shaha AR, Tuttle RM, Narayana A, Wolden SL, Rosenzweig KE, Chong LM, Lee NY: Intensity-modulated radiation therapy for the treatment of nonanaplastic thyroid cancer. Int J Radiat Oncol Biol Phys 2005, 63:1419-26.

14. Lee NY, O'Meara W, Chan K, Della-Bianca C, Mechalakos JG, Zhung J, Wolden SL, Narayana A, Kraus D, Shah JP, Pfister DG: Concurrent chemotherapy and intensity-modulated radiotherapy for locoregionally advanced laryngeal and hypopharyngeal cancers. Int J Radiat Oncol Biol Phys 2007, 69:459-68. 
15. Studer G, Lutolf UM, Davis JB, Glanzmann C: IMRT in hypopharyngeal tumors. Strahlenther Onkol 2006, 182:331-35.

16. Adelstein DJ, Li Y, Adams GL, Wagner H Jr, Kish JA, Ensley JF, Schuller DE, Forastiere AA: An intergroup phase III comparison of standard radiation therapy and two schedules of concurrent chemoradiotherapy in patients with unresectable squamous cell head and neck cancer. $J$ Clin Oncol 2003, 21:92-98.

17. Mendenhall WM, Amdur RJ, Palta JR: Intensity-modulated radiotherapy in the standard management of head and neck cancer: promises and pitfalls. J Clin Oncol 2006, 24:2618-23.

18. Lee NY, de Arruda FF, Puri DR, Wolden SL, Narayana A, Mechalakos J, Venkatraman ES, Kraus D, Shaha A, Shah JP, Pfister DG, Zelefsky MJ: A comparison of intensity-modulated radiation therapy and concomitant boost radiotherapy in the setting of concurrent chemotherapy for locally advanced oropharyngeal carcinoma. Int $\mathrm{J}$ Radiat Oncol Biol Phys 2006, 66:966-74.

19. Veldeman L, Madani I, Hulstaert F, De Meerleer G, Mareel M, De Neve W: Evidence behind use of intensity-modulated radiotherapy: a systematic review of comparative clinical studies. Lancet Oncol 2008, 9:367-75.

20. Adelstein DJ, Lavertu P, Saxton JP, Secic M, Wood BG, Wanamaker JR, Eliachar I, Strome M, Larto MA: Mature results of a phase III randomized trial comparing concurrent chemoradiotherapy with radiation therapy alone in patients with stage III and IV squamous cell carcinoma of the head and neck. Cancer 2000, 88:876-83.

21. Ho KF, Fowler JF, Sykes AJ, Yap BK, Lee LW, Slevin NJ: IMRT dose fractionation for head and neck cancer: variation in current approaches will make standardisation difficult. Acta Oncol 2009, 48:431-39.

22. Keys HM, Roberts JA, Brunetto VL, Zaino RJ, Spirtos NM, Bloss JD, Pearlman A, Maiman MA, Bell JG: A phase III trial of surgery with or without adjunctive external pelvic radiation therapy in intermediate risk endometrial adenocarcinoma: a Gynecologic Oncology Group study. Gynecol Oncol 2004, 92:744-51.

23. Cooper JS, Pajak TF, Forastiere AA, Jacobs J, Campbell BH, Saxman SB, Kish JA, Kim HE, Cmelak AJ, Rotman M, Machtay M, Ensley JF, Chao KS, Schultz CJ, Lee N, Fu KK: Postoperative concurrent radiotherapy and chemotherapy for high-risk squamous-cell carcinoma of the head and neck. N Engl J Med 2004, 350:1937-44.

24. Miyaguchi M, Olofsson J, Hellquist HB: Expression of epidermal growth factor receptor in glottic carcinoma and its relation to recurrence after radiotherapy. Clin Otolaryngol Allied Sci 1991, 16:466-69.

25. Dassonville O, Formento JL, Francoual M, Ramaioli A, Santini J, Schneider M, Demard F, Milano G: Expression of epidermal growth factor receptor and survival in upper aerodigestive tract cancer. J Clin Oncol 1993, 11:1873-78.

26. Rubin J Grandis, Melhem MF, Gooding WE, Day R, Holst VA, Wagener MM, Drenning SD, Tweardy DJ: Levels of TGF-alpha and EGFR protein in head and neck squamous cell carcinoma and patient survival. J Natl Cancer Inst 1998, 90:824-32.

27. Bonner JA, Harari PM, Giralt J, Azarnia N, Shin DM, Cohen RB, Jones CU, Sur R, Raben D, Jassem J, Ove R, Kies MS, Baselga J, Youssoufian H, Amellal N, Rowinsky EK, Ang KK: Radiotherapy plus cetuximab for squamous-cell carcinoma of the head and neck. NEng/ J Med 2006, 354:567-78.

28. Ang KK: Phase III randomized study of concurrent accelerated fractionated radiotherapy and cisplatin with versus without cetuximab in patients with stage III or IV squamous cell carcinoma of the oropharynx, hypopharynx, or larynx. Protocol RTOG-0522. [http:// www.cancer.gov/search/ ViewClinicalTrials.aspx?cdrid=458049\&version=HealthProfessional\&proto colsearchid=4920187]. Accessed January 25, 2007

doi: 10.1186/1748-717X-5-37

Cite this article as: Huang et al., Intensity modulated radiotherapy with concurrent chemotherapy for larynx preservation of advanced resectable hypopharyngeal cancer Radiation Oncology 2010, 5:37

\section{Submit your next manuscript to BioMed Centra and take full advantage of:}

- Convenient online submission

- Thorough peer review

- No space constraints or color figure charges

- Immediate publication on acceptance

- Inclusion in PubMed, CAS, Scopus and Google Scholar

- Research which is freely available for redistribution

Submit your manuscript at www.biomedcentral.com/submit
C Biomed Central 